\title{
"He wants to know how all those people got in there": Surveying The Gods Must Be Crazy through a post- and neo-colonial telescope
}

\begin{abstract}
Roie Thomas
The popular film The Gods Must Be Crazy (1980) remains, despite its age, the primary reference point for Westerners with regard to the San people of southern Africa (commonly known outside Africa as the Bushmen). It is a catalyst for tourist interest in the people since many tourists, as this paper demonstrates, credulously accept the mythology that the San people live now as (and where) they do in the film. Indeed, a Lonely Planet 'coffee-table' publication of 2010 cites the film as mandatory viewing for tourists prior to visiting Botswana. The San's lifestyle is depicted in the film as one of Garden-of-Eden tranquility, although the landscape is somewhat more arid than the Genesis idyll. The San had been driven out of the Kalahari by the Botswana government in the interests of diamond mining, big-game hunting and high-end tourism. Meanwhile, tourist ephemera in-country extols the lifestyle of the Bushmen esoterically, producing imagery that suggests they are still living as they did for millennia, omitting any mention of their modern realities and perpetuating a lie about their ongoing relationship with lands to which they no longer have access. The film is explored here via some thematic distinctions of Spurr (1993). This paper transcribes these distinctions (or tropes) of colonialist thought and action as neo-colonialist which are ubiquitously in operation within the modern tourism industry, perpetuating disempowerment to a significant extent.
\end{abstract}

Keywords: Botswana, Bushmen, hegemony, Kalahari, neo-colonialism, San, tropes, 'Tswana

\section{Introduction}

In this article, I establish the feature film The Gods Must Be Crazy (1980) firmly within my definition of tourist text, i.e, a text not only commercially purpose-produced for tourist consumption but one that, perhaps inadvertently, generates a wave of tourist interest. As will be demonstrated, this film still informs the misconceptions of many tourists regarding the San people. It is shown to be a case in point of Monaco's observation (2000) of the mimetic effect whereby "the politics of film and the politics of 'real life' are so closely intertwined that it is generally impossible to determine which is the cause and which is the effect" (p.262).

The rhetorical categories or tropes developed by Spurr (1993) and elucidated in Section 2, are used as an organisational tool for analysing this particular tourist text, showing that the structures along the spectrum of colonialist rhetoric identified by Spurr often operate concurrently. This may serve as a metaphor for the inherent heterogeneity of cultures, often dismissed in a colonialist mindset in favour of convenient, essentialising, monolithic generalisations. I therefore propose, with the Kalahari San as case in point, that the tropes of Spurr (1993) can be transcribed as neo-colonialist and are ubiquitously in operation within the tourism industry, perpetuating disempowerment in some cases and acting as a catalyst for self-empowerment in others

\section{Defining the tropes}

Dennis Kwek (2003) acknowledges the pertinence of The Rhetoric of Empire (Spurr, 1993) to the structures of a new globalised world: "[t]he first step towards an alternative to colonial discourse ... has to be a critical understanding of its structures; and this 
understanding would be an insider's because we read the discourse from a position already contained by it" (Prasad, 2003: p.142). The following are the main tropes distinguished by Spurr, and used in the analysis in Section 3.

- Appropriation, ${ }^{1}$ in the old colonialism, is concerned with the acquisition of land and labour and resources for Empire, while in neo-colonialism, Appropriation is specifically manifest in the form of exploiting cheap labour.

- Aestheticization sees a narrative approach to reality which sets the real world and its people at a remove from the observer.

- Classification performs a "policing function, assigning positions, regulating groups, and enforcing boundaries" (Spurr, 1993, p. 63).

- Debasement in colonial discourse is about the production of rhetoric and imagery that actively sets out to vilify.

- Negation is the effective dismissal of a race and its culture by way of deliberate omission or subtle undermining.

- Affirmation occurs whereby idealised values of a dominant culture, such as science and progress are endorsed.

- Idealization sets up the "use" of colonised peoples in a largely symbolic manner by Europeans and Americans for their own political purposes.

- Naturalization assumes that natural laws determine the natural superiority of the coloniser over primitive peoples because the former is "civilised" and the latter lives in a state of nature, the antithesis of civilization;

- Eroticization involves the use of "metaphors, seductive fantasies expressions of sexual anxiety - in which the traditions of colonialist and phallocentric discourses coincide" (ibid, p.170).

- Resistance articulates and responds to the colonial enterprise from the opposing perspective, manifest in myriad forms, some combative, some passive, some imaginative, subtle, clever.

A few more notions need to be defined. The tourist gaze, a term coined by Urry (1990) has psycho-political connotations, and makes a natural corollary with the social distance of privilege. The gaze concept is inscribed by Spurr in colonial terms as Insubstantialization, a "phenomenology of consciousness" (ibid, p.142) drawn as fantastical representations of the 'Other' by the West. At its heart it implies an imbalance of power and dovetails also with Spurr's trope of Surveillance, namely the point at which colonised people are first observed by the colonising power: "[g]azed upon, they are denied the power of the gaze; spoken to, they are denied the power to speak freely" (ibid, p.13). This recalls Mary Louise Pratt's "monarch of all I survey" trope (Pratt, 1990) that underscores the colonial project and the neo-colonialist dynamic of supremacy and subjugation at work in most capitalist arenas. Pratt's analogy is that of the panoramic shot commonly used by Victorian explorers to help the audience at home "see" what the explorer had witnessed/discovered. Pratt observes that this monarch-of-all-I-survey scene involves "explicit interaction between aesthetics and ideology" to produce a colonial mentality (ibid, p. 205). As Charles Sugnet (1991) has it, though travellers are, in modern times, not literally in an imperialist position over those under their gaze, and may well be offended by the suggestion of any such complicity, "he (sic) still arrogates to himself the

\footnotetext{
${ }^{1}$ Spurr's tropes of colonialist rhetoric are capitalised and italicised throughout so as to distinguish their contextual usage from more general interpretations of the terms. Also, please note the use of British English throughout the thesis except when employing Spurr's tropes or quoting other texts using U.S English.
} 
rights to representation, judgement and mobility that were the effects of empire" (ibid, p.85).

However, as Stronza (2001) argues, this wielding of power by tourists in the way they look at locals need not always have negative outcomes; that locals can often play a role in encounters with tourists by "turning back the gaze" (p.272) and using initiative and creativity: "[i]f the tourist gaze does indeed have power to act as a mirror and, ultimately, transform the identity of the people gazed on ... tourism has as much potential to revive old values as it does to destroy them" (p.271). In this way, tourism can become a reflexively empowering enterprise fostering mutual respect and inter-cultural awareness.

Finally, it should be noted that Spurr has constructed his argument around the concept of a continuum of the colonial (and neo-colonial) experience; resistance being the proverbial "last straw" when subjugated peoples have had enough, eventually realising and challenging the extent of their oppressed state. The continuum is not slavishly sequential, however. While in most colonialist and neo-colonialist contexts, Surveillance will naturally occur first, followed by Appropriation, with Resistance as an eventual response to the colonial project, the nine tropes between these three are often evident in a range of combinations and this inter-changeability will be demonstrated throughout

\section{The tropes in The Gods Must Be Crazy}

James Monaco (2000) asks whether the voice of any film is "operating in good faith ... [is it] an honest discourse?" (p. 411). The discourse of the film, in this regard, is honest if extrapolated to reflect the neo-colonial dynamic of Tswana hegemony in modern Botswana at the expense of ethnic minorities. As the present analysis shows, however, the text is demonstrably dishonest by way of omission and connotation, as well as being more overtly disingenuous in places.

The narrator's tenor in the film, with its aristocratic accent of imperial authority, is serene and knowledgeable with a slightly bemused quality, eliciting trust and suggesting benevolent paternalism. The device of the omniscient narrator, giving information in the colonial discourse and in documentary style supports an impression of verisimilitude, the colonial code being accepted as interpretive and dominant. In keeping with Spurr's concept of Affirmation, the decision to have the Coke bottle fall from the sky (the domain of the gods, evident in the Bushmen in the film exercising the universal code of looking upwards to the deities) equates a common synecdoche of Western materialism with the assumption of the continuity and inevitability of supremacy. The Coke bottle is simultaneously a paradigmatic connotation (in that the brand has almost universal iconic status) and a syntagmatic connotation (in its contrast with the depicted world of the Bushmen that precedes and immediately follows this scene).

The film's voice-over, after flying close to the trope of Negation when it narrates: "[The Kalahari is] devoid of people, except for [pause/sweet music] the little people of the Kalahari", subsequently demonstrates Idealization with apparently no concession to irony: "they must be the most contented people in the world. They have no crime, no punishment, no violence, no laws, no police, judges, rulers or bosses ... In this world of theirs, nothing is bad or evil ... for the most part they live in complete isolation, quite unaware that there are other people in the world". While such Idealization might be considered acceptable given the vintage of the film, the same sentiments are evident in a recent brochure for Bona Safaris (cited in Sylvain 2005, p. 364): "this race of people is ancient - as shown in their ability to store fat reserves in their buttocks, to be used when food is scarce. Bushmen live on game and wild fruit. They are still mainly hunters and gatherers ... unable to comprehend what happens beyond their world". The filmmaker's 
selection of nursery-style music and cartoonesque sound effect enhances the notion of San childish innocence and wonder, also evident in stereotype. Nicks (1999) notes that the stereotyping epitomised in cultural representations of Indigenous peoples for tourists, even when depictions are apparently positive, undermines any progress towards autonomy: "as long as people in mainstream society think of [Indigenous] cultures as something that existed only in the past and of ... people as having no role in mainstream history and society, they will not be inclined to take seriously the aspirations of First Nations" (Phillips and Steiner, 1999, pp. 313-314).

The Gods Must Be Crazy indulges in some amusing personifications of white-man arrogance via the character Jack Hinds, owner of a safari lodge, a character the audience is positioned to dislike. His ignorance and assumption of the right to appropriate (San protagonist) Xi's desert skills for the benefit of exactly those whose blood-lust for big game has partly caused San eviction from the Central Kalahari is certainly afforded no narrative sympathy. It clearly reflects the mind-set of the tourist industry, perpetuating the entrenchment of perceptions and thus socio-political positions, as shown in (1). Hinds' use of the pronoun 'him' referring to $\mathrm{Xi}$, rather than 'his skills' (quite apart from the obvious Negation of denying Xi a name!) speaks to the Appropriation weltanschuuang of the dominant culture by assuming $\mathrm{Xi}$ is the property of Steyn and also that $\mathrm{Xi}$ has no option but to comply with Hinds' request.

(1) Jack Hinds: I hear you've got a Bushman working for you. Are they good trackers? Mpudi: Best in the world.

Jack Hinds: Mind if I borrow him? One of my guests wounded a cougar. My trackers can't find it.

Peter Davis (1996) critiques The Gods Must Be Crazy as a travelogue, descended from the nineteenth century exploration literature tradition, from which "in the comfort of cinema seats we are shown exotic landscapes, strange peoples and dangerous animals" (p. 82). Superficial interpretations of this film appear to be celebrating the Indigenous, traditional knowledge of the "Bushmen" in the spirit of Idealization, as the narrative introduces: "Where any other person would die of thirst in a few days, they live quite contentedly in this desert ... they know where to dig for roots and bugs and tubers and which berries and pods are good to eat. And of course they know what to do about water".

More enlightened deconstruction, however, peels away the rhetoric to expose underlying tourist assumptions that these skills are still ubiquitously practised by the San in the Kalahari. This film, created by a white South African, must, suggests Davis (1996), be read in the political context of the Student Revolt of 1976, now more commonly known as the Soweto Massacre. Set in Botswana, the film's plot is allegorical, an inverted metaphor for the power imbalance of black South Africans and the army who subverted them. Davis analyses the plot as metaphor:

\footnotetext{
Who are these 'gods' who are crazy? They are the technologically advanced whites whose very garbage is a source of wonder to the Third World. In his simple wisdom, the Bushman rejects what white society has to offer, symbolised by the discarded Coca-Cola bottle ... the Bushmen do not covet the white standard of living and so can never be rivals for it. This might have been a desirable state of affairs for white South Africans, but it was far from the reality of the masses demanding their rightful share of the South African pie (p. 87).
}

While Davis is obviously critical of the established hegemony, his reference to the Bushman's "simple wisdom" and the assumption that they "do not covet" may be read as 
unwittingly patronising per se, unless it is consciously deployed as ironic critique of the film's infantilising narrative tone, along with a satirical comment on the assumption that those considered "lesser" do not aspire to an affluent lifestyle or position of power. In keeping with Spurr's trope of Aestheticization, the stark contrast between the image and reality in the film is highlighted by Le Roux and White (2004) where, the authors posit, the film-maker feeds into the myth that a group with no internal conflict, living in complete harmony with nature actually exists: "the popularity of ... The Gods Must Be Crazy has fuelled and once more exposed this fascination, and also serves to illustrate the problems with the romanticized myth. The implication of this film is that the slightest contact with modernity ... wreaks havoc upon the fragile society of the San" (ibid, p. 72). Le Roux and White assert that the San have long been thought to be incapable of change, bringing about an agenda of protectionist segregation from other groups, and justified their representational exploitation: "although The Gods Must Be Crazy was one of the biggest box office successes of the past century, none of its revenues came back to the San, apart from the remuneration for the main actor, who died destitute in 2003"' (ibid).

In accord with Davis, Paul Weinberg (1997) cites the many aestheticized moving images of the Bushmen appropriated for Western consumption inspired by the success of The Gods Must Be Crazy. Other feature films and numerous advertisements made in recent years have, Weinberg claims, "drawn on traditional San culture as an exotic backdrop to their story lines. In the world of celluloid, Bushmen are always dressed in skins, carrying bows and arrows and dancing around fires" (p. 15). Indeed, in The Gods Must Be Crazy, M'pudi, who speaks a San language, ${ }^{2}$ genuinely loves the San and credits them for saving his life in the desert years before. But his affectionate tone is one of Aestheticization, referring to $\mathrm{Xi}$ as the "little Bushman" and to his people generally as the "sweetest little buggers". Infantilisation is also manifest in the fact that the film presumes to "translate" the San people's thoughts in the manner of parents believing they can accurately decode their babies' or toddlers' thoughts pre-speech, as well as San interpretations of strange phenomena, both natural: "Sometimes they hear a thundering sound when there are no clouds in the sky and they assume the gods have eaten too much again and their tummies are rumbling up there" - and man-made: "Xi saw a most amazing animal approaching. Its legs went round and round instead of up and down ... There was another god. He had a fire inside him and the smoke came out through his mouth and nostrils". Such interpretations draw the San as innocents, justifying their exclusion from the political domain.

Given this deliberate marginalisation, the humour of this film is insulting, according to Davis's reading, in that the realities it so easily dismisses through slapstick are deeply tragic. The film shows several examples of the interface with the white man's world causing the Bushmen harm, but each is downplayed through the use of vaudeville, specifically undercranking, creating the illusion of high speed and including the ubiquitous coke bottle twice falling from the sky, hitting a child on the head, its appropriation as a weapon in family spats, as well as $\mathrm{Xi}$ accidentally driving the landrover at high speed in reverse and being chased by a lion when forced to track a cougar for a safari group: "All these people scurrying across the landscape ... colliding with comic pratfalls, constitute a distorted microcosm of the clash of peoples, customs and ideologies ... the never-never land that the architects of apartheid would have us believe in, where their intentions are for the good of everyone" (ibid, p. 85). The "comic" reversal of the tall Tswana man running with his hands up away from Xi when Xi momentarily

2 The film tacitly assumes there is only one San language, as Afrikaaner ecologist Steyn asks his assistant M'pudi: "You speak Bushman?" and miraculously, M'pudi speaks precisely Xi's dialect. 
picks up "a strange stick" (a gun) is ironic when analysed in the light of the San's relocation and position in modern Botswana, but was clearly not meant to be read as such.

The San has been established for the viewer as posing no social or political threat, so the scene is merely a comedic device. As an aside, the use of slapstick is very effective in these scenes. The comedy in this particular scene derived superficially from the incongruity of Xi's diminutive size in relation to the long rifle and, more profoundly, from his subordinate position in the dynamic between characters. Xi's pervasive attitudes of bewilderment and wonderment in his encounters with the "civilized" world is evident through facial expression and body language, functioning as an "indexical, metonymic system of meaning' (Monaco, 2000, p. 175).

Classification occurs at the point in the narrative where the voice-over describes protagonist $\mathrm{Xi}$ conversing easily with the monkey who steals the Coke bottle. Where there is no successful dialogue between $\mathrm{Xi}$ and other human characters in the film (apart from M'pudi, whose translation of San language is Western and literalist - as he says to Steyn: "I understand the words but what they mean?" - providing limited understanding of Xi's predicament) there is apparently no such misunderstanding between $\mathrm{Xi}$ and the monkey, to whom Xi vigorously argues a case for the evil status of the Coke bottle until the monkey relents and throws it down. Discourse Classification, then, places Xi on an evolutionary scale closer to the animals than to other humans, as does the observation of Gordon (1992) that "White South Africans believed that land was available for the asking in an area they dubbed 'Bushman land and baboon country"' (Gall, 2001, p. 8) and, as with the characteristic meshing of Spurr's categories, such Classification dovetails with Negation and Debasement.

Manfred Rolfes, (2009) calls up MacCannell's notion of staged authenticity, the construction of reality and authenticity for tourists by the operators, so to foreground culture and ethnicity as the observational schema, while "poverty is pushed into the background" (ibid, p. 20). In this way, the "poverty is semantically charged as a cultural tour" (ibid, p. 19). Rolfe gives the example of township tours in South Africa where the context inextricably links history, traditions and ethnicity [read: black population] with poverty, so to further relativise socio-economic differences as essentially cultural. Weinberg, having interviewed Kgau/'hana, the star of both The Gods Must be Crazy movies recounts his shock on first meeting the film's central character whose lifestyle and appearance was "not quite the image I was expecting from a film star who has made his producers millions of rands ... he says he was paid just R5000 for the second [claiming] "the film makers ripped me off"' (ibid, p. 15). This appears to be based on the convenient Negation underlying most forms of Appropriation, which is also explicitly expressed by the film's narrator: "the one characteristic that really makes the Bushmen different from all other races on earth is the fact that they have no sense of ownership at all. Where they live, there's really nothing you can own, only trees and grass and animals". M'pudi, too, the film's unofficial San advocate, apparently accepts the myth of the San needing nothing, evident at the point where, once all the drama is over and Xi's period of "parole" is completed, Andrew Steyn hands Xi money as payment for his work.

(2) M'pudi: He can't use that stuff.

Steyn: I have to.

M'pudi: Bushmen don't know about money.

Steyn: Well, what else can I give him?

M'pudi: There's nothing here he can use. Bushmen don't need things.

Steyn: He's got to take the money. It's the law ...

M'pudi: I'm going to miss the little bugger. 
As Xi walks off, the money floats away on the breeze. The law Steyn refers to is, of course, Tswana law founded on, and faithful to, the British system of jurisprudence, a case of cultural Affirmation showing again the manner in which Spurr's tropes (and their manifestations in reality) can inter-relate. The court scene where $\mathrm{Xi}$, not understanding the concept of ownership, is accused of killing a goat from a herd, found guilty and subsequently incarcerated, serves as a metaphor for the futility of the San case over their eviction from the CKGR. M'pudi's thwarted role as interpreter and tacit advocate for $\mathrm{Xi}$ in court can be metaphorised as the interventions of Survival International and other bodies on the San's behalf. Xi's refusal of food while in a cell can be read as a passive and ultimately ineffectual attempt at Resistance, a situation which can only be rectified by Steyn and M'pudi releasing him for their own purposes, lest, as M'pudi predicts: "he's gonna die, for sure".

Releasing Xi from his incarceration at the hands of the dominant culture, relative sizing in the film serves to symbolically negate the San, not only via Xi's people's diminutive stature represented against the immensity of the Kalahari but also at the point in the film where Steyn and M'pudi appropriate Xi from the jail, lift him onto the vehicle's bonnet effortlessly, giving a sense of his weightlessness, which, alongside his incapacitation (at the hands of a Tswana landowner) is a further metaphor for his people's disenfranchisement. Wearing (2001) asserts that the positioning of tourism within a capitalist framework and its associated relations of power usually means that local communities do not have control over their representation, their culture having been commodified by promoters external to the community. Marketers are careful to present only aspects of culture that would appeal to tourists and to whitewash that which is too difficult for tourists to process into their pre-existing concept of the reality.

In the film, Steyn's research assistant M'pudi has great respect for the ancient skills of Xi's people, evident at the point in the film where he pronounces Xi ecologically better informed than Steyn, yet the film promotes the misconception that the San still live the way they did for millennia and are not part of the modern era. The ignorance of tourists in the $21^{\text {st }}$ century is based on such depictions, fostering an Idealization that whitewashes the realities of dispossession and the struggles for recognition in a modern society. San intelligence is also endorsed in The Gods Must be Crazy where the prison officer agrees to release Xi into the custody of Steyn and his assistant M'pudi, but the officer, in an example of Negation, doubts $\mathrm{Xi}$ can be of any use, since he has no experience or qualifications, an assessment that is roundly rejected in (3), with a case of Appropriation, as Steyn intends to appropriate Xi's expertise to his own research purposes.

(3) M'pudi: He got qualifications! [to Steyn] He could teach you things about plants and animals.

Steyn: Yes! We want to employ him as an ecological expert!

As Davis (1996) observes with regard to another scene in the film, it was a scientist's idea to tranquilize the guerillas, and the scientist's drug (a 'superior totem') used on the sleeping kidnappers, administered by Xi who, "a child in size, can mingle easily with the captured black children ... [who did not use his own soporific drug because] that would have made it Bushman magic and not White Man's magic" (p. 87). Certainly there is the condescending infantilization of the Aestheticization trope, evident in the hostage scene of the film where Steyn, M'pudi and Xi, looking down from a hilltop see schoolchildren and their (white South African) teacher herded by kidnappers. Xi has a look through the telescope and M'pudi comments to Steyn: "He wants to know how all those people got in 
there". Then, when the plan to tranquilise the kidnappers is concocted, $\mathrm{Xi}$ is disguised as a child and shown how to administer the soporific, whereupon Steyn instructs M'pudi: "Tell [Xi] he must dip the needle each time", simultaneously exhibiting ignorance of the fact that ancient San hunting techniques used precisely this technique to tranquilise animals, alongside an assumption of white scientific superiority. $\mathrm{Xi}$ demonstrates innovation and stealth in the implementation of his mission and M'pudi comments, "Yeah, he's clever".

The trope of Naturalization also comes into play where a group is thought to be naturally beyond the realities of the central culture. Reference has been made to tourists' perceptions that "[San] hardly suffer from funny diseases ... because of the type of food they eat". In contrast, the reality is expressed by John Hardbattle, founder of the First People of the Kalahari (FPK) organisation, who, as Kiema (2010) acknowledges:

... felt that our traditional practice of sharing had been eroded, that our cultural links and networks had been affected, that alcohol abuse among us had become entrenched to the point it was almost considered as 'culture', often accompanied by theft, something previously unknown to us. He told us that we had become a landless underclass, prone to disease (p. 91).

An example of apparently gratuitous Eroticization is to be noted during the commentary early in the film where the camera, in sharp focus close-up, dwells for several seconds on a single file of San bottoms. In my long experience of sharing this film with school classes, this particular scene, as with the slapstick scenes previously cited, elicits great hilarity among students and has, in consequence, given me pause. The notion of Eroticization in travel discourse is often infused with machismo, with the same overtones of conquest, argues Noy (2007). The semiotics deployed are typically aligned to war, competitive sports and patriarchy. The voice-over commentary in The Gods Must be Crazy is certainly infused with the undertones of conquest, the "virgin", untouched landscape and innocent people penetrated by the more powerful, even destructive, colonialists, the tone allowing for the poignancy of this, while concurrently stressing the inevitability of the subjugation, analogous to the bittersweet emotions of a father 'giving away' his daughter as a bride.

The utopian scenes of the San lifestyle in the Kalahari to which Xi returns in a triumphant denouement, having discarded the evil coke bottle, constitute a feel-good fabrication. In the above representations, then, Negation is clearly at play in the easy dismissal of San rights by way of madcap comedy, infantilisation, as well as a systemic assimilationist policy denying, even under the guise of altruism, any future of traditional knowledge and cultural uniqueness outside a representational framework.

The geographic proximity of the world suggested to be hitherto outside the San's experience is shown in to be fast encroaching, so there is a sense that Xi's desert nirvana approaches its imminent demise, the assumption of inevitability simultaneously justifying government policies and enhancing 'doomed race' Aestheticization /Idealization of the San in the tourist imaginary. Lekoa's documentary film (Lekoa, 2007) shows tourists on the "San walk" who are not averse to articulating their ignorance. One tourist says, when (San guide) Size creates fire using two sticks, "There are many cultures that start fires with sticks. I have never seen it before. I thought it was a kind of legend". Lekoa comments that it is little wonder many tourists will believe whatever they are manipulated to believe (personal interview, September, 2010). Spurr's trope of Idealization comes into play, where a group is no threat, so the dominant culture can afford to use glowing rhetoric about the strengths of the Other, since it is now only of historical interest - apart from situations where it is carefully contained and contrived for tourists, as the ingenuously idealised comments of the tourists in Lekoa's documentary attest: "Yes [but] 
it should be alive also. It's not good enough to have it in the history books. It survived for 20000 years so it would be a shame to have it not survive the modern world".

\section{Conclusion}

As a first-year teacher I took my Year Ten students from a tiny country town two hundred kilometres to the state capital to watch the newly released The Gods Must Be Crazy. I had just seen it myself and told them it was hilarious and wonderful. The first ten minutes of this film play like a 1960s newsreel, with a mellifluous British voice-over and "facts" about the Bushmen given in neat info-bites, juxtaposed with scenes of frenetically crazy life in Johannesburg, about which the Bushmen are blissfully unaware. My recalcitrant fifteen year-olds sat there grumbling - "she's brought us all this way for a documentary?" But then, of course, the Coke bottle falls from the sky and the fun begins.

Some years after that first viewing, I saw an episode of Foreign Correspondent (Australian Broadcasting Corporation, 2002) and was shocked and mortified. The people no longer lived in desert serenity. According to the report, the San had been driven out of the Kalahari by the Botswana government in the interests of diamond mining, big-game hunting and high-end tourism. The San's ancient skills of hunting and gathering, of finding water in an apparently waterless land had been all but lost. The family groups remaining in the remote area were, claimed the report, dependent on government handouts, many were alcoholic, apparently rudderless.

Meanwhile, tourist ephemera in-country extols the lifestyle of the Bushmen esoterically, producing imagery that suggests they are still living as they did for millennia, omitting any mention of their modern realities and perpetuating a lie about their ongoing relationship with lands to which they no longer have access. It struck me that a form of bourgeois nationalism - a substitute form of colonialism - was operating in this context. With the help of Spurr (1993), I have here tried to substantiate the impression of neocolonialism in Botswana, by elucidating and classifying the imagery and rhetoric the film, as well as in tourism publications. The analysis demonstrates, I believe, that many of the same preconceptions, attitudes and practices of the colonial era are still very much evident in postcolonial Botswana.

Recently I was invited to stay in a small township created by the Botswana government outside the British-designated Central Kalahari Game Reserve (CKGR) to accommodate the evictees from the Kalahari. Such villages make up a "gulag of special settlements" (Good, 2008: p.183) that tourists rarely see, from which San elders are trucked to luxury safari lodges within the CKGR, made to don their traditional garb, to take tourists on survival treks, and trucked back at the end of the day, lending truth to Scott's (1990) observation that "while the dominant ideology does not entirely exclude the interests of subordinate groups, it operates to conceal or misrepresent aspects of social relations that, if apprehended directly, would be damaging to the interests of dominant elites" (pp.71-72).

My mission with this investigation became one of exposing the mismatch between representation and reality, between myth and truth. I freely admit to the fact that while I critique unfavourably the common tourist exoticisation of certain Indigenous communities, my entire investigation into representation of the San is borne of a captivation with this group that amounts to the same sensibility. Therein lies responsibility for the academic and the tourist: to be constantly self-reflective.

\section{Acknowledgements}

I wish to thank the reviewers of this article for generously giving of their time and for 
their meticulous attention to detail. Also, I gratefully acknowledge my friend Dithunya Lekoa whose research in the resettlement villages outside the CKGR provided much of the empirical evidence of common tourist credulity as regards the San. It is such scholarship as hers that eventually effects change for the better.

\section{References}

Australian Broadcasting Corporation. (2002). Foreign correspondent: The Bushmen of Botswana. http://www.abc.net.au/foreign/stories/s710265.htm

Davis, P. (1996). In darkest Hollywood: Exploring the jungles of cinema's South Africa. Athens, OH.: Ohio University Press.

Gall, S. (2001). The Bushmen of southern Africa: Slaughter of the innocent. London: Chatto \& Windus.

Good, K. (2008). Diamonds, dispossession and democracy in Botswana. Oxford: James Currey.

Kiema, K. (2010). Tears for my land: A social history of the Kua of the Central Kalahari Game Reserve, Tc'amnqoo. Gaborone: Mmegi Publishing House.

Kwek, D. (2003). Decolonizing and re-presenting culture's consequences: A postcolonial critique of cross-cultural studies in management. In A. Prasad (Ed.) Postcolonioal theory and organizational analysis: A critical engagement. New York, NY: Palgrave Macmillan.

Lekoa, D. S. (2007). Culture on sale. (documentary film) Visual Cultural Studies, Trømso: University of Trømso.

Le Roux, W., and White, A. (2004). Voices of the San. Cape Town: Kwela Books.

MacCannell, D., 1999. The Tourist. Los Angeles: University of California Press.

Monaco, J. (2000). How to read a film: Movies, media and beyond. (3rd ed). New York: Oxford University Press.

Nicks, T. (1999). Indian villages and entertainments: Setting the stage for tourist souvenir sales. In R.B. Phillip \& C.B. Steiner (Eds). (1999). Unpacking culture: Art and commodity in colonial and postcolonial worlds, pp.301-315. Los Angeles, CA: University of California Press.

Prasad, A. (Ed) (2003). Postcolonial theory and organizational analysis: A critical engagement. New York, NY.: Palgrave Macmillan.

Pratt, M.L (1992). Imperial eyes: Travel writing and transculturation. London. Routledge.

Noy, C. (2007). Travelling for masculinity: The construction of bodies/spaces in Israeli backpackers' narratives. In P. Pritchard, N. Morgan, I. Ateljevic and C. Harris (Eds.). Tourism and gender: Embodiment, sensuality and experience, pp. 47-72. Wallingford: CABI.

Rolfes, M. (2009). Poverty tourism: Theoretical reflections and empirical findings regarding an extraordinary form of tourism. In GeoJournal, citeulike (online). (Retrieved 30/5/10). www.citeulike.org/journal/springerlink-102895

Scott, J. C. (1990.) Domination and the arts of resistance: Hidden transcripts. New Haven, CT: Yale University Press.

Spurr, D. (1993). The rhetoric of empire: Colonial discourse in journalism, travel writing and imperial administration. London: Duke University Press.

Stronza, A. (2001). Anthropology of tourism: Forging new ground for ecotourism and other alternatives, Annual Review of Anthropology, 30, 261-283.

Sugnet, C. (1991). Vile bodies, vile places: Travelling with Granta. Transition 51, 70-85. 
Sylvain, R. (2005). Disorderly development: Globalization and the idea of culture in the Kalahari. American Ethnologist, 32 (3), 354-370.

Wearing, S. (2001). Volunteer Tourism: Experiences That Make a Difference. Oxon: CABI.

Weinberg, P. (1997). In search of the San. Johannesburg, South Africa: The Porcupine Press.

Uys, J. (1980). The gods must be crazy. New Realm/Mimosa/CAT.

Author address

33 Veulalee Avenue. Trevallyn, Tasmania, Australia, 7250

Roie.Thomas@utas.edu.au

Tel: +61 3437160005

About the author

Roie Thomas is a university tutor and secondary English teacher in Tasmania, Australia. Her doctoral research was a semiotic analysis of tourism texts depicting the San in Botswana, drawing upon postcolonial theory. 